\title{
Subsite-Specific Dietary Risk Factors for Colorectal Cancer: A Review of Cohort Studies
}

\author{
Anette Hjartåker, ${ }^{1}$ Bjarte Aagnes, ${ }^{2}$ Trude Eid Robsahm, ${ }^{2}$ Hilde Langseth, ${ }^{2}$ \\ Freddie Bray, ${ }^{3}$ and Inger Kristin Larsen ${ }^{4}$ \\ ${ }^{1}$ Department of Nutrition, Institute of Basic Medical Sciences, University of Oslo, P.O. Box 1046 Blindern, 0317 Oslo, Norway \\ ${ }^{2}$ Department of Etiological Research, Cancer Registry of Norway, Institute of Population-Based Cancer Research, 0304 Oslo, Norway \\ ${ }^{3}$ Section of Cancer Information, International Agency for Research on Cancer, 69372 Lyon, France \\ ${ }^{4}$ Department of Registration, Cancer Registry of Norway, Institute of Population-Based Cancer Research, 0304 Oslo, Norway
}

Correspondence should be addressed to Anette Hjartåker; anette.hjartaker@medisin.uio.no

Received 11 October 2012; Accepted 30 November 2012

Academic Editor: Anne-Kathrin Illner

Copyright (C) 2013 Anette Hjartåker et al. This is an open access article distributed under the Creative Commons Attribution License, which permits unrestricted use, distribution, and reproduction in any medium, provided the original work is properly cited.

\begin{abstract}
Objective. A shift in the total incidence from left- to right-sided colon cancer has been reported and raises the question as to whether lifestyle risk factors are responsible for the changing subsite distribution of colon cancer. The present study provides a review of the subsite-specific risk estimates for the dietary components presently regarded as convincing or probable risk factors for colorectal cancer: red meat, processed meat, fiber, garlic, milk, calcium, and alcohol. Methods. Studies were identified by searching PubMed through October 8, 2012 and by reviewing reference lists. Thirty-two prospective cohort studies are included, and the estimates are compared by sex for each risk factor. Results. For alcohol, there seems to be a stronger association with rectal cancer than with colon cancer, and for meat a somewhat stronger association with distal colon and rectal cancer, relative to proximal colon cancer. For fiber, milk, and calcium, there were only minor differences in relative risk across subsites. No statement could be given regarding garlic. Overall, many of the subsite-specific risk estimates were nonsignificant, irrespective of exposure. Conclusion. For some dietary components the associations with risk of cancer of the rectum and distal colon appear stronger than for proximal colon, but not for all.
\end{abstract}

\section{Introduction}

Global estimates for 2008 indicate that colorectal cancer is the third most common cancer in the world [1]. Reports in several countries have described diverging incidence rates in colorectal cancer by subsite, including, in relative terms, an increasing proportion of proximal tumors [2-15], and thus a shift in absolute incidence from left- to right-sided colon cancers.

The reasons for this trend are not well understood; the subsites differ in physical function, artery supply, histology, and innervation, and they also derive from different segments in the primitive intestinal tract in the embryo [16]. The proximal colon originates from the midgut, whereas the distal colon and the rectum derivate originate from the hindgut.
Comparisons have also shown that proximal colon tumors tend to have different molecular characteristics, with a higher proportion of microsatellite instability, and are more likely to have $\mathrm{CpG}$ island methylator phenotype and Ki-ras mutations than distal colon and rectal tumors [17].

It has been estimated that 45 percent of all colorectal cancer cases can be prevented in high-risk populations through modifications of diet, physical activity habits, and weight control [18]. According to the recent report from the World Cancer Research Fund/American Institute for Cancer Research (WCRF/AICR), there is convincing evidence that dietary fiber protects against colorectal cancer and that red and processed meat and alcohol (particularly in men) increase the risk of the disease [19]. Further, it is stated that garlic, milk, and calcium probably protect 
TABLE 1: Search results as of October 8, 2012.

\begin{tabular}{llc}
\hline & Queries & Result \\
\hline 1 & Search colorectal neoplasms & 148374 \\
2 & Search risk factors & 745969 \\
3 & Search diet & 332911 \\
4 & Search nutrition & 259739 \\
5 & Search alcohol & 718622 \\
6 & Search cohort study & 1253216 \\
7 & Search 3 OR 4 OR 5 & 1215492 \\
8 & Search 2 AND 7 & 81363 \\
9 & Search 1 AND 8 & 2099 \\
10 & Search 6 AND 9 & 627 \\
11 & Search case control study & 622385 \\
12 & Search review & 2082039 \\
13 & Search 10 NOT 11 NOT 12 & 356 \\
14 & Search 13 Limits: Human, English & 341 \\
\hline
\end{tabular}

against colorectal cancer. No distinction is, however, made for the different subsites of the colorectum [19]. Also, although meta- [20-23] and pooled analyses [24-26] have provided quantitative synthesis for several of the dietary risk factors, little emphasis has been placed on subsite risks.

Based on the biological differences in the colorectal segments and the reported differences in incidence, we may suggest differences across the segments in their association to lifestyle factors, such as diet. The aim of the present paper is to give an updated overview summarizing the etiological differences between the colorectal subsites with regard to the dietary factors considered to be convincing or probable risk factors for colorectal cancer.

\section{Material and Methods}

The specific risk factors studied were red meat, processed meat, fiber, garlic, milk, calcium, and alcohol, selected given an a priori assessment of their importance in colorectal cancer etiology following the WCRF/AICR report in 2011 [19], and for which their modification could lead to a reduction in rates of colorectal cancer. The outcome was the risk of primary colorectal cancer according to subsite.

A search for cohort studies published as original articles was conducted via a search of PubMed (http://www .ncbi.nlm.nih.gov/), using a search strategy that combined the term "colorectal neoplasms" with the terms "risk factors" and "cohort study" with either the term "diet," "nutrition," or "alcohol." The search was restricted to studies published or available online as of October 8, 2012, in the English language. A detailed description of the search strategy and the resulting papers retrieved is given in Table 1 , and the procedure is described in Figure 1. A total of 341 articles were identified and reviewed according to title and abstract. The initial evaluation yielded 108 articles in the study database and underwent a second evaluation based on full-text review. A similar PubMed search for case-control studies nested within a cohort identified 46 articles, of which one underwent full-text review. In addition, further 62 articles were identified by scanning the reference lists of retrieved articles, reviews, meta-, and pooled analyses and underwent full-text review (Figure 1).

Studies were included if they provided risk estimates (and corresponding confidence intervals) for both proximal and distal colon cancer. Proximal colon (right sided) includes ceacum, ascending and transverse colon, while distal colon (left-sided) includes descending colon, sigmoid flexure, and sigmoideum. Some studies have not followed the abovementioned classification [27-29], and this is specified in Table 2. Further, to be included, the cohorts had to be either population based, registry based, or obtained from censuses. Studies on specific subpopulations (e.g., hospitalbased cohorts) were not included nor were studies examining second cancers, metastasis, survival, or mortality. Following the full-text evaluation, 139 articles were excluded for the reasons indicated in Figure 1, and 32 articles were included in the review. Of these, seven gave data on (red) meat [3036], five on processed meat [31-35], eight on fiber [37-44], one on garlic [37], three on milk [45-47], seven on calcium $[28,45,47-51]$, and ten on alcohol [27, 29, 36, 52-58].

The number adds up to more than 32 as several papers give data for more than one risk factor. If several papers on the same risk factor were published for a given cohort, all data was retrieved from the most recent paper. The relative risk (RR), hazard rate ratio (HRR), hazard ratio (HR), incidence rate ratio (IRR) or odds ratio (OR), and corresponding 95\% confidence intervals (95\% CI) for each risk factor are presented (as RR) in Figures 2-8, sorted in ascending order of magnitude by sex. For one study the risk estimates were tabulated according to the lowest versus highest exposure category in the original paper [28] and are presented as the inverse of the value in the corresponding figure (Figure 7).

Meta-analyses were not performed as a consequence of the heterogeneity in factors such as exposure measurement, the categorization of risk factor levels, and the confounders adjusted for in the studies [59].

\section{Results}

Overall, data from 21 cohorts with information on one or more of the risk factors were included in this review. Table 2 gives a detailed description of the studies, with information on cohort size, number of cases, sex, age distribution, followup time, and factors adjusted for in the risk analyses. The European Prospective Investigation into Cancer and Nutrition (EPIC) study consists of subcohorts from 10 European countries. The other cohorts were from the USA (10 cohorts), Sweden (2), Denmark (2), Japan (3), Korea (1), UK (1), and the Netherlands (1). The subsite-specific results (Figures 28) are described according to the individual risk factors, as presented in the following.

3.1. Red Meat. Seven cohort studies were included in the review, of which five reported on red meat [30-33,35], one on beef and pork [34], and one on meat (not further specified) [36]. The five studies on red meat reported an increased risk of colorectal cancer with increasing intake [30-33, 35] (Table 2), 


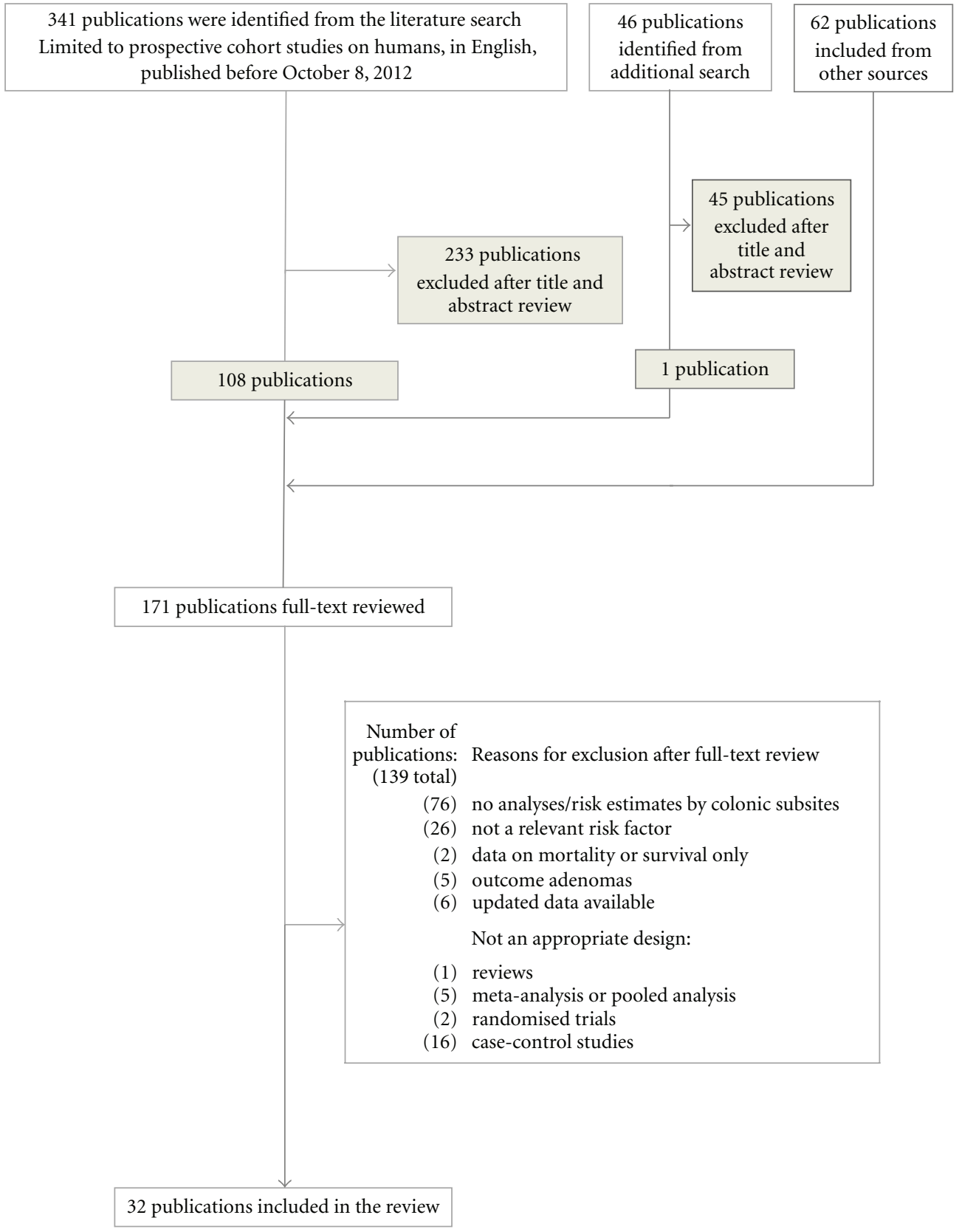

FIGURE 1: Flow diagram of the study selection.

although most of the risk estimates were not statistically different from unity. In Figure 2, there appears to be somewhat more consistency with the observation of an increased risk of cancers of the rectum and distal colon than there is for proximal colon cancer. This picture remains when restricting the evaluation to studies with adequate statistical power. In a Swedish study, women consuming 94 or more grams of red meat per day had an increased risk of distal colon cancer of 2.22 (95\% CI 1.34-3.68) compared to women consuming less than 50 grams/day, and there was a significant trend of increasing risk with increasing consumption $\left(P_{\text {trend }}<\right.$ 0.001) [32]. A long-term high intake of red meat yielded an increased risk of rectal cancer of $43 \%$ (95\% CI 1.00 2.05) relative to low intake in a US study [31], whereas in another US study there was a significant trend of increased risk of both proximal colon, distal colon and rectal cancer with increasing consumption of red meat (including both processed and nonprocessed red meat) (for all $P_{\text {trend }}=0.02$ ) [35].

Neither beef consumption nor pork consumption was significantly associated with risk of cancer of any colorectal subsite in a Japanese study [34], while the frequency of meat consumption (not further specified) was positively associated with proximal and distal colon cancer in South Korean men, 


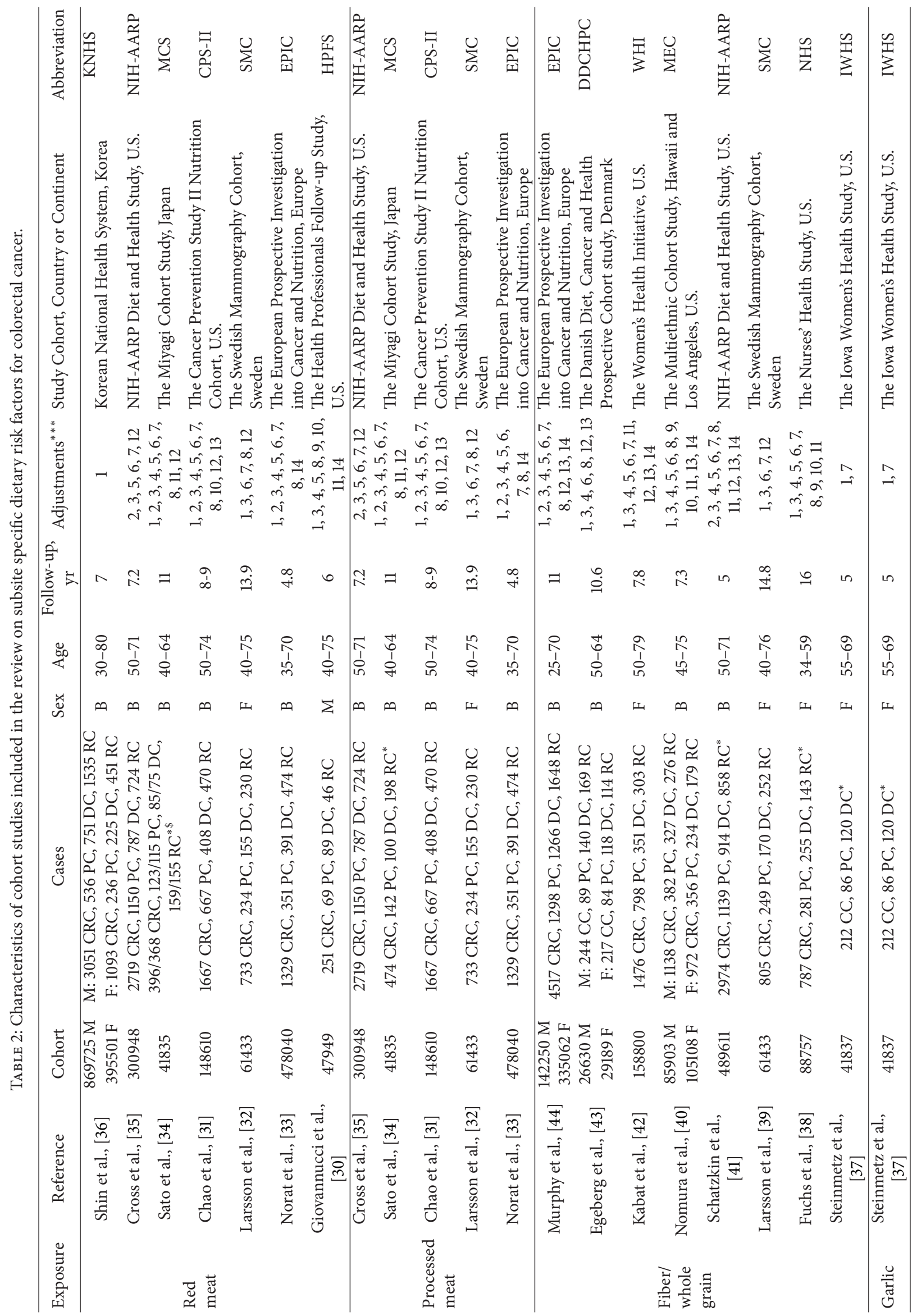




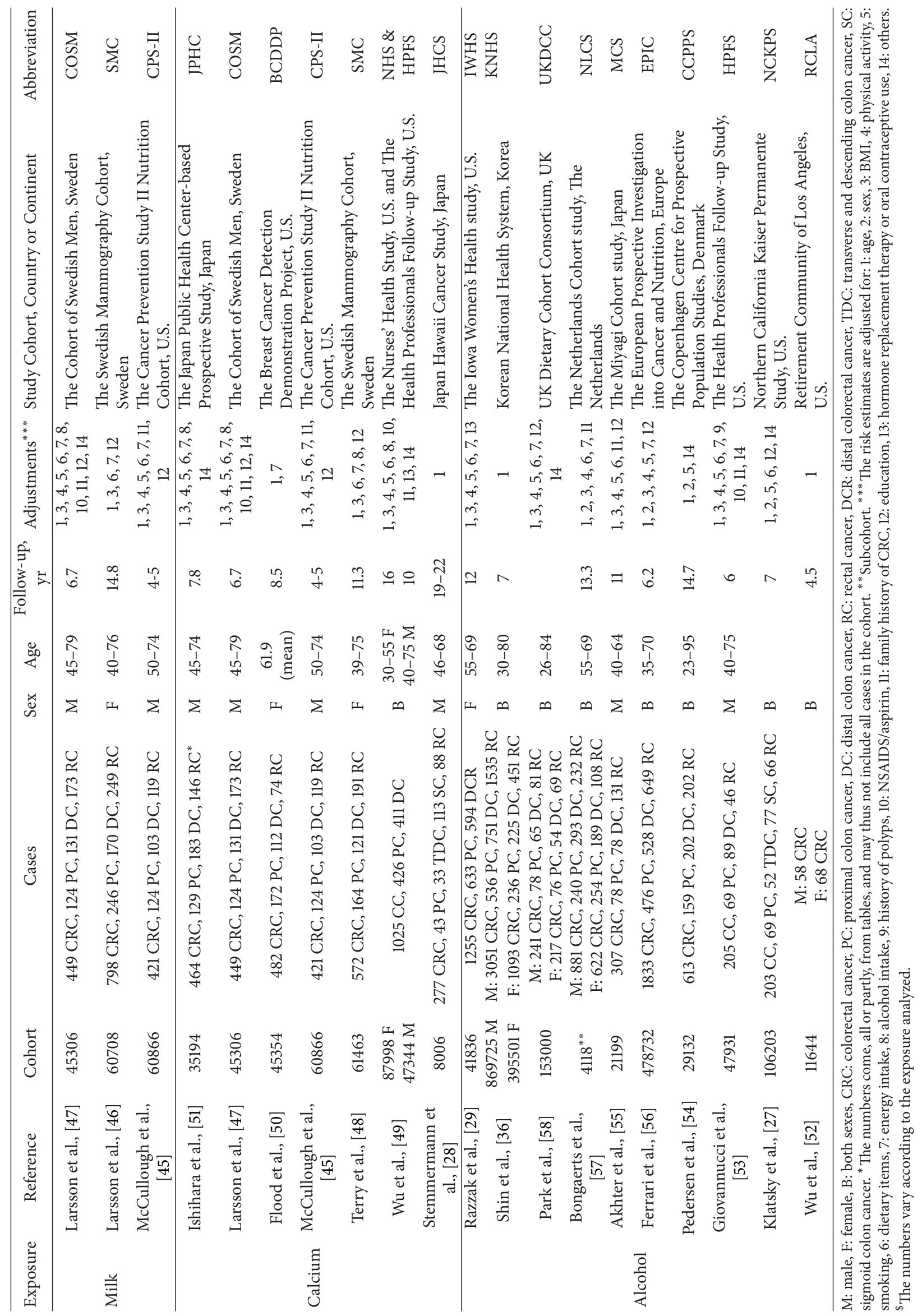




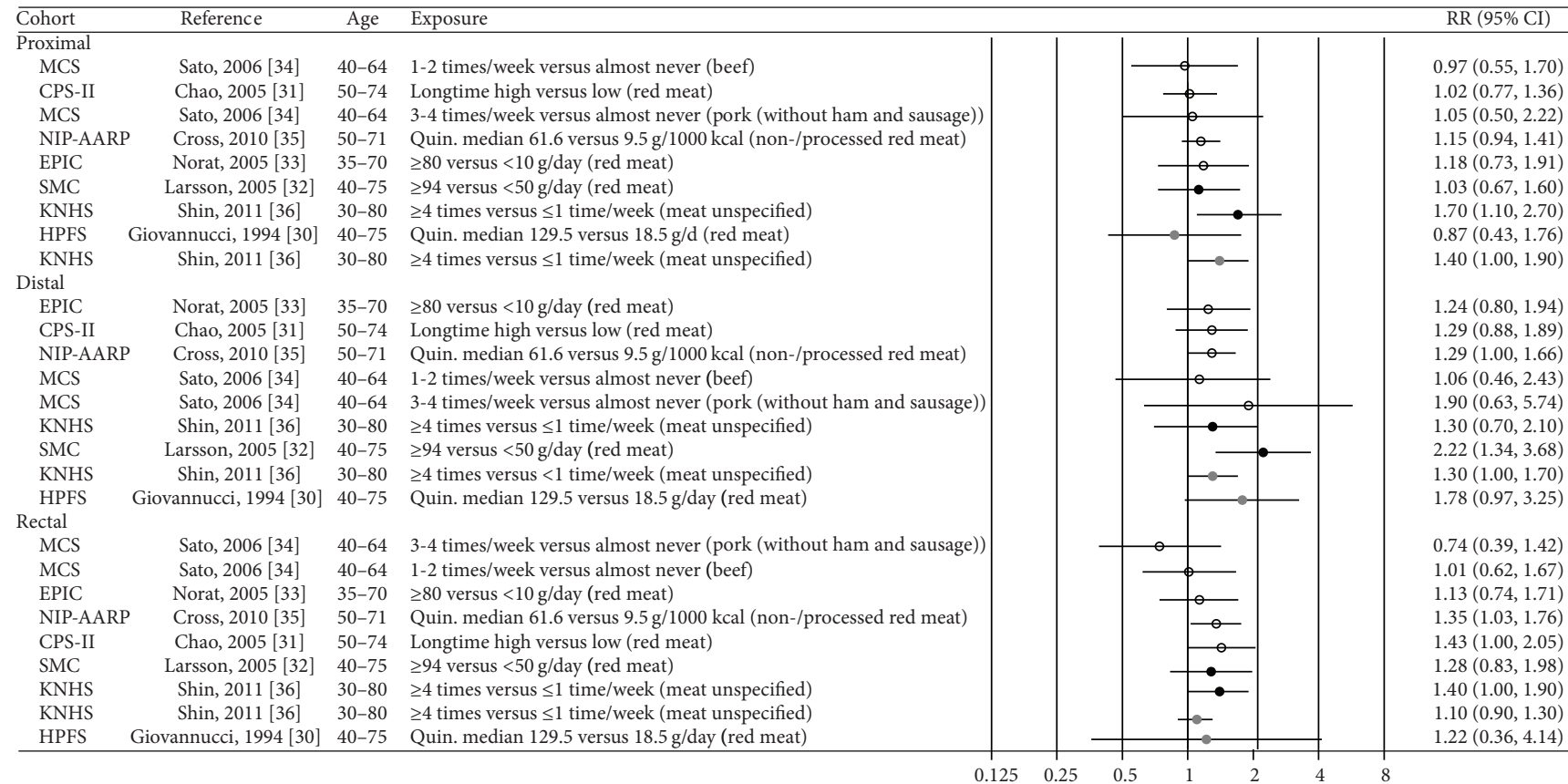

FIGURE 2: Estimates of relative risk with $95 \%$ CI for the highest versus the lowest exposure categories of red meat. (The results are stratified on sex. Open circles: both gender combined. Closed black circles: females. Closed grey circles: men. All estimates are sorted from the lowest to the highest by subsite and sex.)

\begin{tabular}{|c|c|c|c|c|c|}
\hline \multirow{2}{*}{$\frac{\text { Cohort }}{\text { Proximal }}$} & \multirow[t]{2}{*}{ Reference } & \multirow[t]{2}{*}{ Age } & \multicolumn{2}{|l|}{ Exposure } & \multirow[t]{2}{*}{$\mathrm{RR}(95 \% \mathrm{CI})$} \\
\hline & & & & & \\
\hline MCS & Sato, $2006[34]$ & $40-64$ & 3-4 times/week versus almost never (ham and sausage) & - & $0.69(0.32,1.51)$ \\
\hline NIP-AARP & Cross, 2010 [35] & $50-71$ & Quin. median 22.3 versus $1.6 \mathrm{~g} / 1000 \mathrm{kcal}$ (processed meat) & $\theta$ & $1.09(0.89,1.33)$ \\
\hline CPS-II & Chao, 2005 [31] & $50-74$ & Longtime high versus low (processed meat) & - & $1.14(0.87,1.50)$ \\
\hline EPIC & Norat, 2005 [33] & $35-70$ & $\geq 80$ versus $<10 \mathrm{~g} /$ day (processed meat) & & $1.19(0.70,2.01)$ \\
\hline SMC & Larsson, 2005 [32] & $40-75$ & $\geq 32$ versus $<12$ g/day (processed meat) & - & $1.02(0.69,1.52)$ \\
\hline \multicolumn{6}{|c|}{ 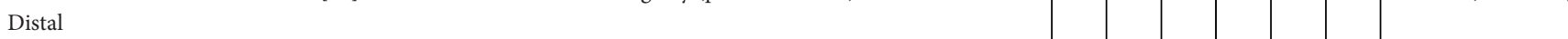 } \\
\hline MCS & Sato, $2006[34]$ & $40-64$ & 3-4 times/week versus almost never (ham and sausage) & + & $0.65(0.28,1.55)$ \\
\hline NIP-AARP & Cross, 2010 [35] & $50-71$ & Quin. median 22.3 versus $1.6 \mathrm{~g} / 1000 \mathrm{kcal}$ (processed meat) & $\theta_{-}$ & $1.10(0.86,1.41)$ \\
\hline EPIC & Norat, 2005 [33] & $35-70$ & $\geq 80$ versus $<10 \mathrm{~g} /$ day (processed meat) & 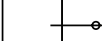 & $1.48(0.87,2.53)$ \\
\hline CPS-II & Chao, 2005 [31] & $50-74$ & Longtime high versus low (processed meat) & $\longrightarrow$ & $1.50(1.04,2.17)$ \\
\hline SMC & Larsson, 2005 [32] & $40-75$ & $\geq 32$ versus $<12 \mathrm{~g} /$ day (processed meat) & - & $1.39(0.86,2.24)$ \\
\hline \multicolumn{6}{|c|}{ - } \\
\hline MCS & Sato, $2006[34]$ & $40-64$ & 3-4 times/week versus almost never (ham and sausage) & & $1.10(0.60,2.03)$ \\
\hline CPS-II & Chao, $2005[31]$ & $50-74$ & Longtime high versus low (processed meat) & 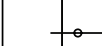 & $1.20(0.87,1.68)$ \\
\hline NIP-AARP & Cross, 2010 [35] & $50-71$ & Quin. median 22.3 versus $1.6 \mathrm{~g} / 1000 \mathrm{kcal}$ (processed meat) & - & $1.30(1.00,1.68)$ \\
\hline EPIC & Norat, 2005 [33] & $35-70$ & $\geq 80$ versus $<10 \mathrm{~g} /$ day (processed meat) & ب & $1.62(1.04,2.50)$ \\
\hline SMC & Larsson, 2005 [32] & $40-75$ & $\geq 32$ versus $<12 \mathrm{~g} /$ day (processed meat) & $\rightarrow$ & $0.90(0.60,1.34)$ \\
\hline
\end{tabular}

FIGURE 3: Estimates of relative risk with $95 \%$ CI for the highest versus the lowest exposure categories of processed meat. (The results are stratified on sex. Open circles: both gender combined. Closed black circles: females. All estimates are sorted from the lowest to the highest by subsite and sex.)

and with proximal colon and rectal cancer in South Korean women [36].

3.2. Processed Meat. Four studies have reported on processed meat $[31-33,35]$ and one has reported on ham and sausages [34] (Table 2). In the EPIC study, consumption of 80 grams or more of processed meat per day conferred a $62 \%$ (95\% CI 1.04-2.50) increased risk of rectal cancer compared to an intake of less than 10 grams per day [33], and in a US study a high long-term intake of processed meat was associated with a 50\% (95\% CI 1.042.17) increased risk of distal colon cancer [31] (Figure 3). In a more recent American study, consuming 22.3 grams or more of processed meat per $1000 \mathrm{kcal}$ increased the risk 


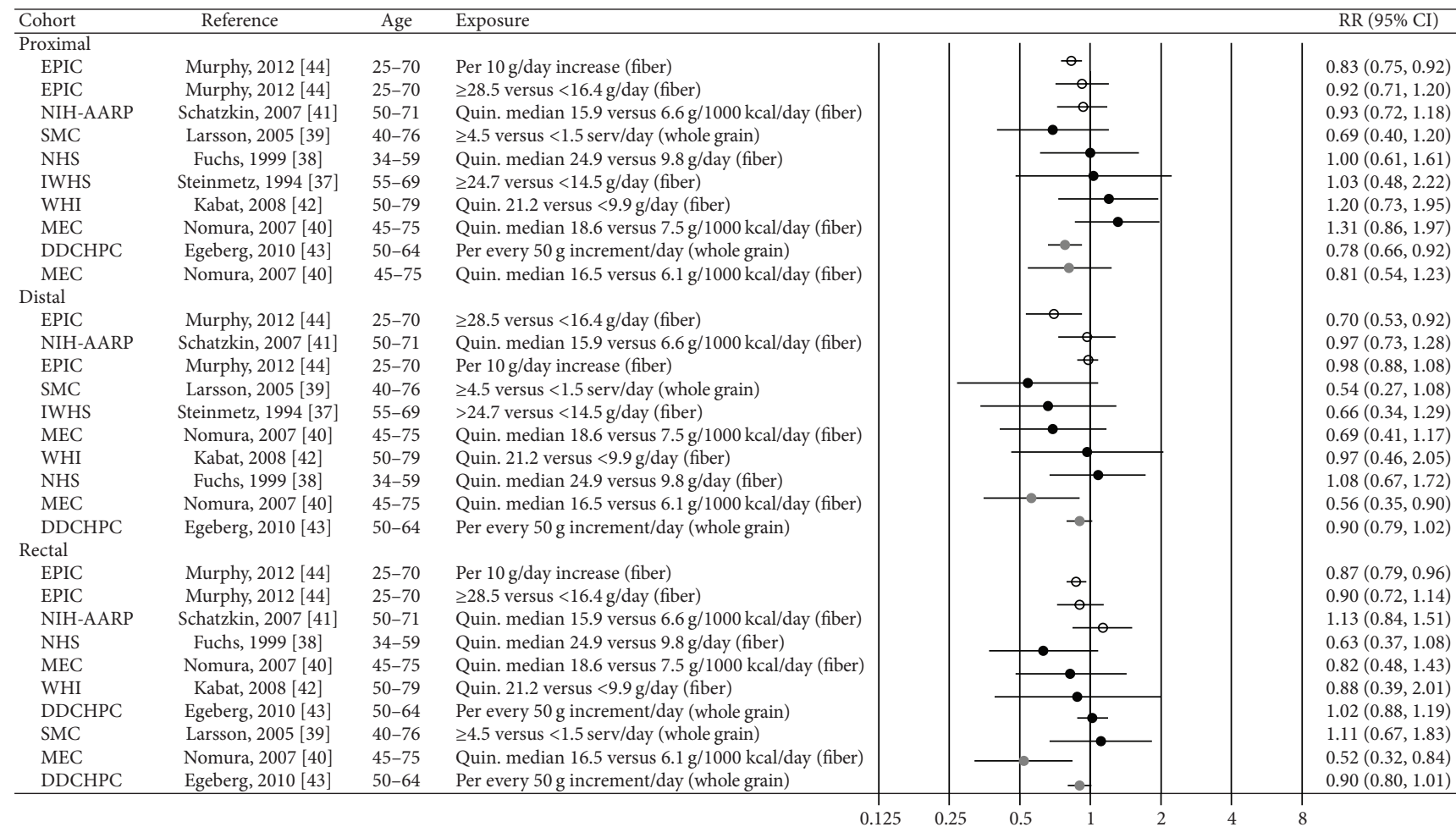

FIGURE 4: Estimates of relative risk with 95\% CI for the highest versus the lowest exposure categories of fiber and whole grain. (The results are stratified on sex. Open circles: both gender combined. Closed black circles: females. Closed grey circles: men. All estimates are sorted from the lowest to the highest by subsite and sex.)

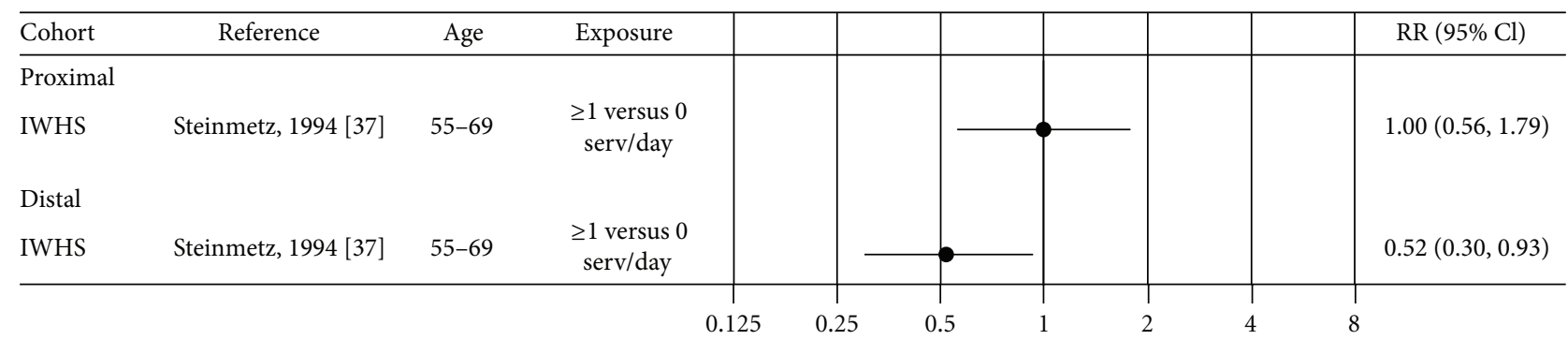

FIGURE 5: Estimates of relative risk with 95\% CI for the highest versus the lowest exposure categories of garlic. (Closed black circles: females.)

of rectal cancer with $30 \%$ (95\% CI 1.00-1.68) compared to consuming 1.6 gram or less per $1000 \mathrm{kcal}$ [35]. No significant associations were seen in Swedish [32] and Japanese studies [34].

3.3. Fiber. Eight cohort studies were included in the review; six have provided estimates for the risk of the colonic subsites in relation to fiber consumption [37, 40-42, 44] and two have provided estimates for the whole grain consumption $[39,43]$ (Table 2). As for fiber, most of the risk estimates were not statistically different from unity [37, 41, 42] (Figure 4). The EPIC study reported an inverse association between fiber intake and colorectal cancer with no strong evidence of different associations across the subsites: when fiber intake was analyzed as a categorical variable, a significant inverse association was seen for distal colon cancer only $\left(P_{\text {trend }}=\right.$ 0.02 ), whereas when fiber intake was analyzed as a continuous variable and corrected for measurement errors, significant inverse associations were seen for proximal colon (HR per 10 gram/day increase $0.83,95 \%$ CI $0.75-0.92$ ) and rectum cancer (HR per 10 gram day/increase $0.87,95 \%$ CI 0.79-0.96), but not for distal colon cancer [44]. The Multiethnic Cohort observed a reduced risk for distal colon and rectal cancer among those in the highest compared to the lowest fiber intake group, but the reduction was only significant in men (RR 0.56, 95\% CI 0.35-0.90 and RR 0.52, 95\% CI 0.32-0.84, resp.) [40].

Two Scandinavian papers have reported on associations between whole grain consumption and cancer risk of colorectal subsites $[39,43]$. In a Danish study, which is also 


\begin{tabular}{|c|c|c|c|c|c|}
\hline \multirow{2}{*}{$\begin{array}{l}\text { Cohort } \\
\text { Proximal }\end{array}$} & \multirow[t]{2}{*}{ Reference } & \multirow[t]{2}{*}{ Age } & \multicolumn{2}{|l|}{ Exposure } & \multirow[t]{2}{*}{ RR $(95 \%$ CI $)$} \\
\hline & & & & & \\
\hline SMC & Larsson, 2005 [46] & $40-76$ & $\geq 1$ serv/day versus never or seldom (full-fat cultured milk) & & $0.80(0.56,1.15)$ \\
\hline SMC & Larsson, 2005 [46] & $40-76$ & $\geq 1$ serv/day versus never or seldom (whole milk) & $\rightarrow$ & $1.58(1.15,2.16)$ \\
\hline CPS-II & McCullough, 2003 [45] & $50-74$ & $\geq 1.1$ serv/day versus none (total milk) & & $0.68(0.42,1.09)$ \\
\hline COSM & Larsson, $2006[47]$ & $45-79$ & $\geq 1.5$ glasses/day versus $<2$ glasses/week (total milk) & & $0.76(0.45,1.30)$ \\
\hline \multicolumn{6}{|l|}{ Distal } \\
\hline SMC & Larsson, 2005 [46] & $40-76$ & $\geq 1$ serv/day versus never or seldom (full-fat cultured milk) & & $0.71(0.44,1.13)$ \\
\hline SMC & Larsson, 2005 [46] & $40-76$ & $\geq 1$ serv/day versus never or seldom (whole milk) & & $0.72(0.47,1.10)$ \\
\hline COSM & Larsson, 2006 [47] & $45-79$ & $\geq 1.5$ glasses/day versus $<2$ glasses/week (total milk) & - & $0.53(0.33,0.87)$ \\
\hline CPS-II & McCullough, 2003 [45] & $50-74$ & $\geq 1.1$ serv/day versus none (total milk) & & $0.92(0.54,1.58)$ \\
\hline \multicolumn{6}{|l|}{ Rectal } \\
\hline SMC & Larsson, 2005 [46] & $40-76$ & $\geq 1$ serv/day versus never or seldom (full-fat cultured milk) & & $0.91(0.62,1.31)$ \\
\hline SMC & Larsson, 2005 [46] & $40-76$ & $\geq 1$ serv/day versus never or seldom (whole milk) & & $0.99(0.72,1.37)$ \\
\hline COSM & Larsson, 2006 [47] & $45-79$ & $\geq 1.5$ glasses/day versus $<2$ glasses/week (total milk) & - & $0.69(0.45,1.06)$ \\
\hline CPS-II & McCullough, 2003 [45] & $50-74$ & $\geq 1.1$ serv/day versus none (total milk) & 一. & $0.89(0.54,1.47)$ \\
\hline
\end{tabular}

Figure 6: Estimates of relative risk with 95\% CI for the highest versus the lowest exposure categories of milk. (The results are stratified on sex. Closed black circles: females. Closed grey circles: men. All estimates are sorted from the the lowest to the highest by subsite and sex.)

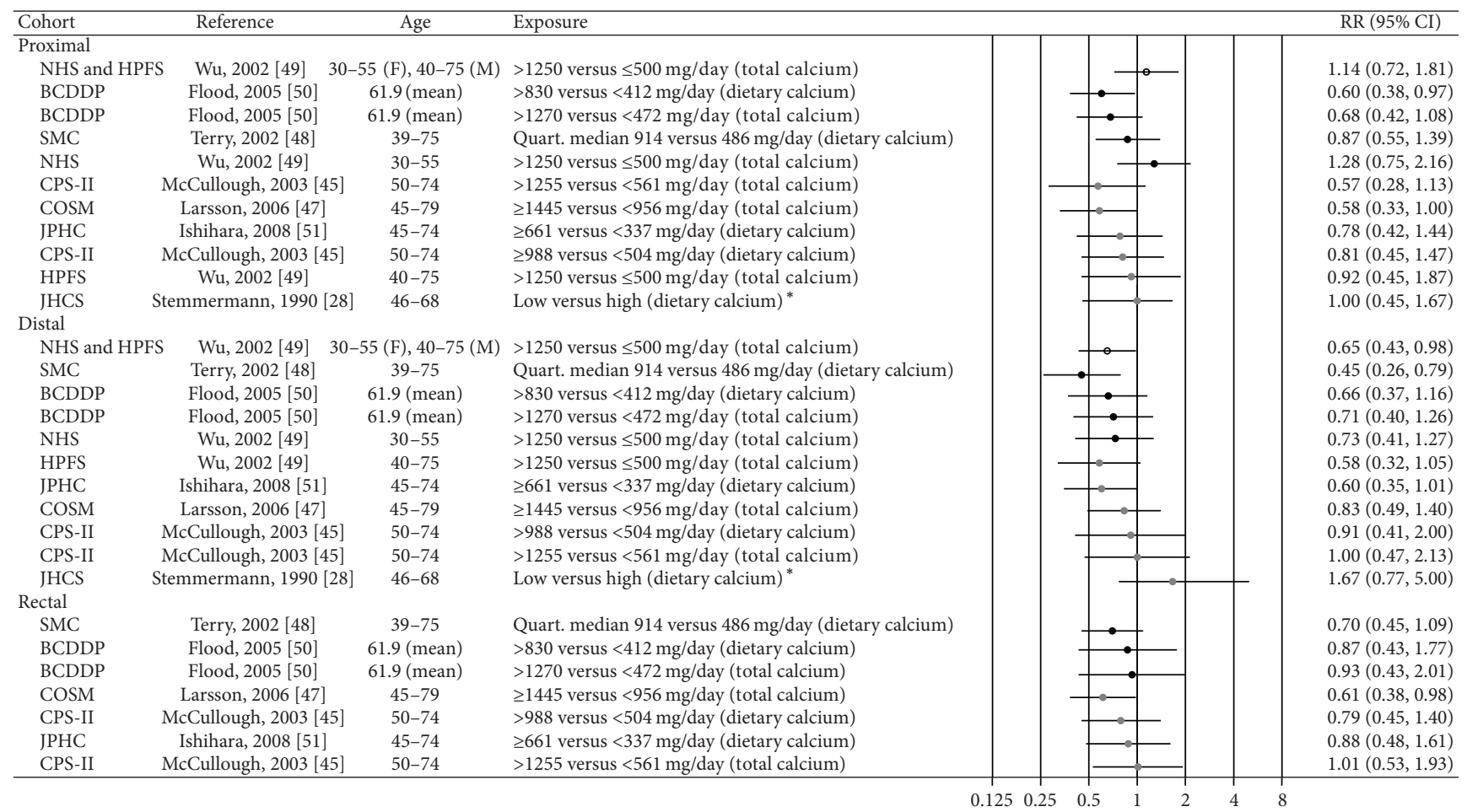

FIGURE 7: Estimates of relative risk with 95\% CI for the highest versus the lowest exposure categories of calcium. (The results are stratified on sex. Open circles: both gender combined. Closed black circles: females. Closed grey circles: men. All estimates are sorted from the lowest to the highest by subsite and sex, except Stemmermann et al. [28].)

included in the EPIC study, total consumption of whole grain products was associated with a significantly lower risk of proximal colon cancer and a borderline significantly lower risk of distal colon cancer and rectal cancer in men (IRR per each increment in intake of 50 gram per day $0.78,95 \%$ CI $0.66-0.92$ for proximal colon, 0.90 , 95\% CI $0.79-1.02$ for distal colon, and $0.90,95 \%$ CI $0.80-1.01$ for rectum) but not in women (data not given) [43]. No significant associations between whole grain consumption and cancer of any of the colorectal subsites were seen in the Swedish Mammography Cohort [39] (Figure 4).

The width of the confidence intervals for the risk estimates on fiber and whole grain varies markedly between the included studies. However, whether all studies are included 


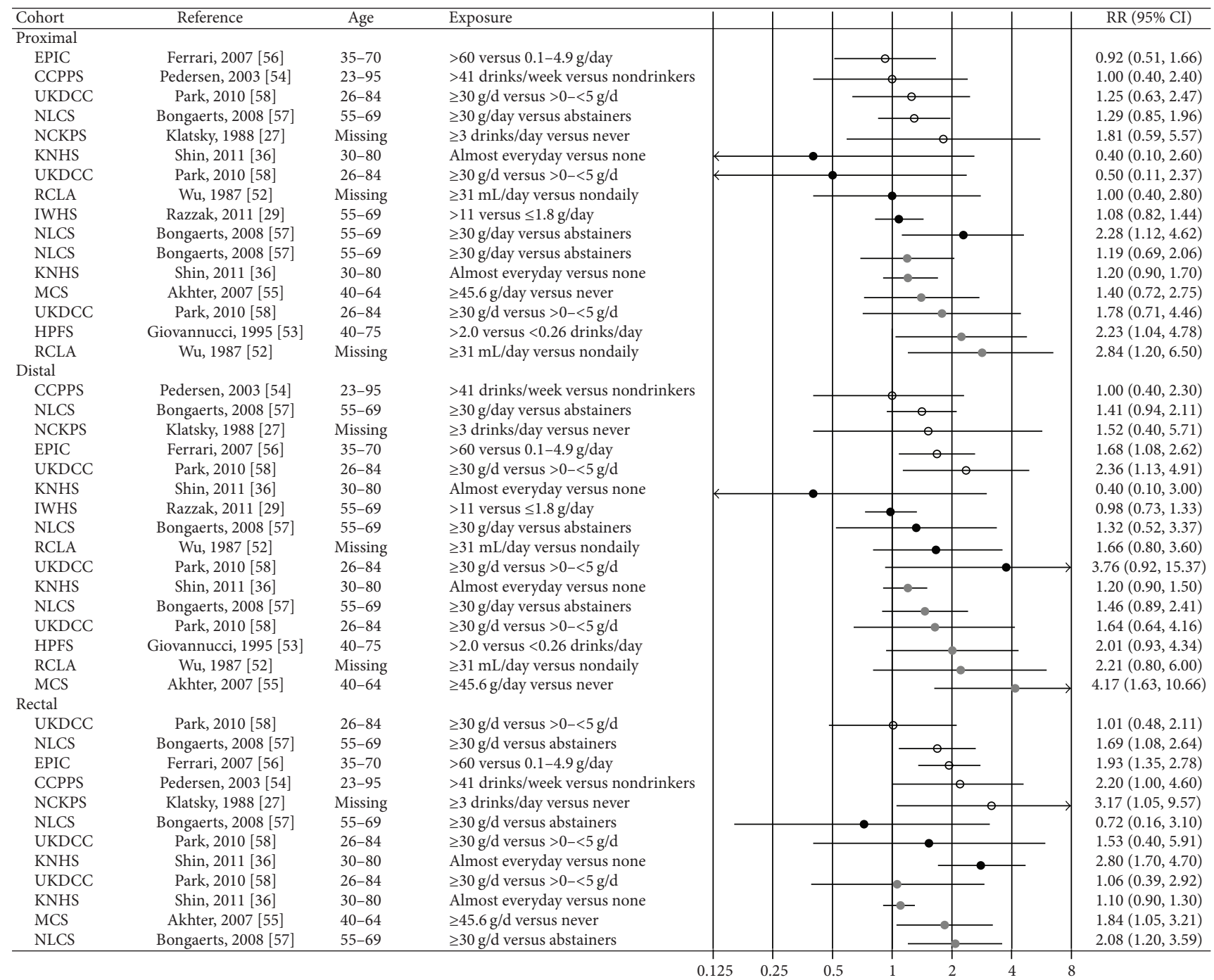

FIGURE 8: Estimates of relative risk with 95\% CI for the highest versus the lowest exposure categories of alcohol. (The results are stratified on sex. Open circles: both gender combined. Closed black circles: females. Closed grey circles: men. All estimates are sorted from the lowest to the highest by subsite and sex.)

or those with the lowest power are excluded, there are rather minimal differences in relative risk across the subsites.

3.4. Garlic. Only one study on garlic is included in the review. The Iowa Women's Health Study reported that having at least one serving per week of garlic was associated with a $48 \%$ reduced risk of distal colon cancer compared to zero servings of garlic (RR 0.52, 95\% CI 0.30-0.93) [37] (Table 2, Figure 5).

3.5. Milk. Three cohort studies were included in the review [45-47]. Two cohort studies have examined the relation between total consumption of milk and the risk of cancer in colorectal subsites $[45,47]$ (Table 2, Figure 6). No significant associations were seen for any of the colorectal subsites in a US study that combined both sexes (estimates not given for women) [45]. In a study of Swedish men, a significantly reduced risk for distal colon cancer was seen for those consuming 1.5 glasses or more of milk per day compared to those consuming less than two glasses per week (RR 0.53, 95\% CI 0.33-0.87) [47].

In another Swedish study restricted to high fat dairy food and conducted among women only, a significant inverse trend was observed between consumption of full-fat cultured milk and risk of distal colon cancer $\left(P_{\text {trend }}=0.03\right)$, whereas a significant increased risk of proximal colon cancer was observed among women who consumed whole milk (1 or more servings per day compared to never/seldom consumers RR 1.58, 95\% CI 1.15-2.16) [46].

3.6. Calcium. Seven papers from eight cohorts were included in the review $[28,45,47-51]$ (Table 2, Figure 7). In the analyses from the Nurses' Health Study and the Health 
Professionals Follow-Up Study that studied colon cancer only, non-significant inverse associations were seen between total calcium and distal colon cancer for both men and women, and a pooled analysis of the two cohorts gave a significant inverse trend for distal colon cancer $\left(P_{\text {trend }}=\right.$ 0.01) [49]. Likewise, a significant inverse trend was reported between total calcium and distal colon cancer in the Swedish Mammography Cohort $\left(P_{\text {trend }}=0.02\right)$ [48], while in a US female cohort, a significant inverse trend was seen between dietary calcium intake and proximal colon cancer $\left(P_{\text {trend }}=0.01\right)$ [50]. No association was seen for total calcium. In a US study examining both sexes, total calcium intake was significantly inversely associated with proximal colon cancer among men $\left(P_{\text {trend }}=0.04\right)$, but not dietary calcium, and there were no significant associations seen for women (estimates not given) [45]. In a study of Swedish men, a significant inverse relation was found between total calcium and rectal cancer $\left(P_{\text {trend }}=0.02\right)$, whereas nonsignificant inverse associations were seen for cancer of the colon [47]. No significant associations between dietary calcium and cancer of any colorectal subsite were reported in a Japanese study either for men or for women (estimates not given for women) [51]. An earlier study of Hawaiian-Japanese men reported a significant inverse association between dietary calcium and sigmoid colon cancer $\left(P_{\text {trend }}=0.02\right)$ [28]. In addition to the eight cohorts included in this paper, an additional cohort study among American women states that their data provided little support for a protective effect of total calcium at either tumor subsite, but does not present risk estimates [60].

3.7. Alcohol. Ten articles [27, 29, 36, 52-58] were included in the review (Table 2). Three analyses for both sexes combined consistently showed a higher risk of rectal cancer with increasing alcohol consumption and no significant associations for any of the colon subsites [27, 54, 57]. In the EPIC study [56] an increased risk was reported both for rectal and distal colon cancer, whereas in the UK dietary cohort consortium (part of which is included in the EPIC study) [58] a significantly increased risk was found for distal colon cancer only (Figure 8). Several sex-specific analyses have been done. Among men, two older studies with limited statistical power reported that alcohol consumption was positively related to proximal colon cancer only [52, 53], whereas four more recent studies reported non-significant associations with proximal colon cancer $[36,55,57,58]$. A study among Japanese men reported increased risk for distal colon cancer, but the confidence interval for the risk estimate was very wide (consumption of 45.6 grams alcohol or more per day compared to never drinkers HR 4.17, 95\% CI 1.6310.66) [55]. In terms of consumption of alcohol and rectum cancer among men, two of four studies have reported a positive association [55, 57].

For women, fewer significant associations have been reported. In the Iowa Women's Health Study, alcohol was not significantly associated with either proximal colon or distal colorectal cancer, nor did further separation into distal colon and rectal cancer reveal any significant associations (estimates not given) [29]. Furthermore, no significant associations were seen in an earlier study of American women
[52] or in the UK dietary cohort consortium [58]. In The Netherlands Cohort Study, however, women consuming 30 grams or more of alcohol per day had HRR of proximal colon cancer of 2.28 (95\% CI 1.12-4.62) compared to abstainers, whereas analyses for the other subsites were not sufficiently robust to draw any conclusions [57]. In a Korean study, women who frequently consumed alcohol or who consumed greater amounts of alcohol had a higher risk of rectal cancer [36].

\section{Discussion}

This review provides an overall and updated synthesis of the results from cohort studies examining the association between dietary factors that are convincingly or probably related to the risk of colorectal cancer and subsite-specific colorectal cancer. Our study indicates that consumption of alcohol is more strongly related to the risk of rectal cancer than to colon cancer, also that meat consumption tends to be somewhat more strongly related to the risk of distal colon cancer and rectal cancer than proximal colon cancer, that there are only minor differences in relative risk for colorectal cancer across the major subsites for fiber, milk, and calcium, and that no statement can be given for garlic due to limited data. It should be noted that for all exposures the majority of the analyses showed nonsignificant associations with cancer risk, the exception being the positive association between alcohol consumption and rectal cancer.

The pathway of colorectal cancer is complex. The subsite etiology is rather poorly understood, and the mechanism for the various dietary factors is likely to differ. Even for red and processed meat, both established risk factors for colorectal cancer, the underlying mechanisms are not well defined. One suggested mechanism for the somewhat stronger association for rectum and distal colon relative to proximal colon cancer relates to the enhanced endogenous formation of carcinogenic N-nitroso compounds with a high intake of meat [61]. The level of markers of N-nitroso compounds appears to be higher in tissue from distal colon and rectum than in that of the proximal colon [62]. This finding is in keeping with a previously meta-analyses which implicated processed meat consumption as a stronger risk factor for cancer occurrence at the distal colon relative to the proximal colon [22].

A suggested mechanism by which dietary fiber may decrease the risk of colorectal cancer is linked to the fermentation of fiber. The fermentation produces short-chain fatty acids and, in particular, acetic, propionic, and butyric acids. Butyrate is particularly of interest, as it has been shown to induce apoptosis and to be cytotoxic to both colorectal adenoma and carcinoma cells [63]. Studies on mice have shown that the concentration of butyrate is highest in the distal colon [64]. In humans, fiber is fermented in the proximal colon, and the total amount of short-chain fatty acids has been estimated to be considerably higher in the proximal site compared to the distal [65]. One study on proximal and distal colonocytes indicates, however, that butyrate is a more important source of energy for the distal, than for the proximal, colonic mucosa [66]. If so, this 
could be a relevant biological mechanism explaining any differences in risk between the sites. In addition, fiber may dilute the concentration of carcinogenic substances in the distal colon. Despite these findings, a pooled analysis on fiber reported no convincing differences in colorectal risk for the various anatomical subsites [25], in line with our own results published here.

The reduced risk of colorectal cancer with increasing consumption of milk is likely to be at least partly mediated by calcium, which is thought to have a protective effect through its ability to bind bile acids, and its growth-restraining and differentiation- and apoptosis-inducing effect on colorectal cells [67]. No convincing site-specific associations regarding milk and calcium were seen in our review. A former pooled analysis reported an inverse association for milk limited to cancer of the distal colon and rectum [24], while the results from two meta-analysis on site-specific impact of calcium have been conflicting $[20,21]$.

The consumption of alcohol is associated with increasing risk of cancer in several organs in the digestive tract, including the colorectum [18]. Alcohol is not a carcinogen itself, but acts as a tumor promoter and possibly as a cocarcinogen. Alcohol also acts as a solvent and thus might increase the exposure to other carcinogens by enhancing the penetration of carcinogens into the cell [18]. Acetaldehyde is a metabolite of alcohol and may be the most important agent responsible for the carcinogenic effect as it is highly toxic, mutagenic, and carcinogenic [68]. A pooled analyses on alcohol reported similar risk across all areas of the large bowel [26]. However, a stronger association with alcohol for rectal cancer compared with colon cancer as seen in our paper could possibly be related to a higher degree of epithelial hyperregeneration in rectum [69]. The number of sex-specific analysis is presently too low to suggest any significant interaction by sex at the subsite level.

There are some methodological issues in this study which may have impacted on the findings. There is considerable variability in several key characteristics of the assembled cohort studies: the follow-up time across studies included in this paper varied from 4 to 22 years, while the total number of colorectal cancer cases analyzed ranged from 126 to 2974. Short-term follow-up studies tend to accrue a lower number of cases, and the resulting estimates are subject to greater uncertainty. The substratification of cases by sex, tumor location, and exposure categories, as presented here, inevitably leads to smaller numbers and a greater degree of imprecision in the estimates, even for relatively large studies. Statistically significant associations may thus be more spurious at the subsite-specific level. However, restricting the evaluation to studies with adequate statistical power did not change the overall picture. Long-term follow-up studies will commonly accrue a greater number of cases, but are more prone to measurement error given that an increasing follow-up time raises the possibility that exposure status of the participants will change, leading to misclassification of exposure and under- or overestimation of the risk estimates. However, the natural history of colorectal cancer is on average of long duration, and exposure in the more distant past may be the most relevant when estimating subsequent risk.
Another issue is the difference in risk factor dosages between studies and that the categories compared sometimes vary considerably between studies. For instance, for calcium, in the Swedish study by Larsson et al. [47] daily intake of $1445 \mathrm{mg}$ or more is compared to an intake of less than $956 \mathrm{mg} /$ day, whereas in the Japanese study by Ishihara et al. [51] daily intake of $661 \mathrm{mg}$ or more is compared with an intake of less than $337 \mathrm{mg} /$ day. Careful reading of the exposure categories (given in the figures) is therefore necessary when evaluating the findings. In addition, the specific confounding factors adjusted for at the analysis stage differ between studies.

Of the studies that were full-text reviewed, 76 were excluded as they did not reveal information at the level of subsite location. Given the high proportion of cohort studies failing to report subsite-specific estimates, the potential publication bias prohibited a formal meta-analysis [59]. A further rationale for this decision is the lack of uniformity in exposure categories within each risk factor.

In summary, the strength of the association between dietary components and cancer of the large bowel may partially depend on the anatomic location within the colorectum. The most consistent finding is the stronger association between alcohol and rectal cancer, compared with alcohol and proximal and distal colon cancer. Meat (red and processed) is possibly more strongly associated with risk of distal colon cancer and rectal cancer than the risk of proximal colon cancer. For fiber, milk, and calcium there seem to be only minor differences in relative risk across the subsites. However, caution is required as the number of papers presenting risk estimates by colorectal subsite is limited, particularly for milk and garlic. Also, most of the subsite-specific analyses report non-significant findings.

\section{Conflict of Interests}

The authors declare that they have no conflict of interests.

\section{Acknowledgment}

The authors thank Lena Leder for her contribution to the data extraction and paper preparation.

\section{References}

[1] J. Ferlay, H. R. Shin, F. Bray, D. Forman, C. Mathers, and D. M. Parkin, GLOBOCAN 2008: Cancer Incidence and Mortality Worldwide, IARC Cancer Base, no. 10, International Agency for Research on Cancer, Lyon, France, 2012.

[2] F. Kee, R. H. Wilson, R. Gilliland, J. M. Sloan, B. J. Rowlands, and R. J. Moorehead, "Changing site distribution of colorectal cancer," British Medical Journal, vol. 305, no. 6846, p. 158, 1992.

[3] G. I. Slater, R. H. Haber, and A. H. Aufses Jr., "Changing distribution of carcinoma of the colon and rectum," Surgery, Gynecology \& Obstetrics, vol. 158, pp. 216-218, 1984.

[4] Y. Toyoda, T. Nakayama, Y. Ito, A. Ioka, and H. Tsukuma, "Trends in colorectal cancer incidence by subsite in Osaka, Japan," Japanese Journal of Clinical Oncology, vol. 39, no. 3, pp. 189-191, 2009. 
[5] C. Cucino, A. M. Buchner, and A. Sonnenberg, "Continued rightward shift of colorectal cancer," Diseases of the Colon and Rectum, vol. 45, no. 8, pp. 1035-1040, 2002.

[6] S. L. Saltzstein and C. A. Behling, "Age and time as factors in the left-to-right shift of the subsite of colorectal adenocarcinoma: a study of 213,383 cases from the California Cancer Registry," Journal of Clinical Gastroenterology, vol. 41, no. 2, pp. 173-177, 2007.

[7] R. W. Beart, L. J. Melton, M. Maruta, M. B. Dockerty, H. B. Frydenberg, and W. M. O'Fallon, "Trends in right and left-sided colon cancer," Diseases of the Colon \& Rectum, vol. 26, pp. 393398, 1983.

[8] F. Levi, L. Randimbison, and C. La Vecchia, "Trends in subsite distribution of colorectal cancers and polyps from the Vaud Cancer Registry," Cancer, vol. 72, no. 1, pp. 46-50, 1993.

[9] E. Mitry, A. M. Benhamiche, C. Couillault et al., "Effect of age, period of diagnosis and birth cohort on large bowel cancer incidence in a well-defined French population, 1976-1995," European Journal of Cancer Prevention, vol. 11, no. 6, pp. 529534, 2002.

[10] H. Singh, A. A. Demers, L. Xue, D. Turner, and C. N. Bernstein, "Time trends in colon cancer incidence and distribution and lower gastrointestinal endoscopy utilization in Manitoba," American Journal of Gastroenterology, vol. 103, no. 5, pp. 12491256, 2008.

[11] H. Takada, T. Ohsawa, S. Iwamoto et al., "Changing site distribution of colorectal cancer in Japan," Diseases of the Colon \& Rectum, vol. 45, pp. 1249-1254, 2002.

[12] M. Thörn, R. Bergström, U. Kressner, P. Sparén, M. Zack, and A. Ekbom, "Trends in colorectal cancer incidence in Sweden 1959-93 by gender, localization, time period, and birth cohort," Cancer Causes and Control, vol. 9, no. 2, pp. 145-152, 1998.

[13] J. R. Jass, "Subsite distribution and incidence of colorectal cancer in New Zealand, 1974-1983," Diseases of the Colon \& Rectum, vol. 34, pp. 56-59, 1991.

[14] R. Scheiden, P. Pescatore, Y. Wagener, N. Kieffer, and C. Capesius, "Colon cancer in Luxembourg: a national populationbased data report, 1988-1998," BMC Cancer, vol. 5, article 52, 2005.

[15] I. K. Larsen and F. Bray, "Trends in colorectal cancer incidence in Norway 1962-2006: an interpretation of the temporal patterns by anatomic subsite," International Journal of Cancer, vol. 126, no. 3, pp. 721-732, 2010.

[16] F. Y. Li and M. D. Lai, "Colorectal cancer, one entity or three," Journals of Zhejiang University-Science B, vol. 10, pp. 219-229, 2009.

[17] M. L. Slattery, K. Curtin, R. K. Wolff et al., "A comparison of colon and rectal somatic DNA alterations," Diseases of the Colon \& Rectum, vol. 52, no. 7, pp. 1304-1311, 2009.

[18] World Cancer Research Found and American Institute for Cancer Research, Food, Nutrition, Physical Activity, and the Prevention of Cancer: A Global Perspective, Washington, DC, USA, 2007.

[19] World Cancer Research Found and American Institute for Cancer Research, Food, Nutrition, Physical Activity, and the Prevention of Colorectal Cancer. Continuous Update Project, Colorectal Cancer Report 2010, Summary, Washington, DC, USA, 2011.

[20] M. Huncharek, J. Muscat, and B. Kupelnick, "Colorectal cancer risk and dietary intake of calcium, vitamin $\mathrm{D}$, and dairy products: a meta-analysis of 26,335 cases from 60 observational studies," Nutrition and Cancer, vol. 61, no. 1, pp. 47-69, 2009.

[21] J. A. Bergsma-Kadijk, P. van't Veer, E. Kampman, and J. Burema, "Calcium does not protect against colorectal neoplasia," Epidemiology, vol. 7, no. 6, pp. 590-597, 1996.

[22] S. C. Larsson and A. Wolk, "Meat consumption and risk of colorectal cancer: a meta-analysis of prospective studies," International Journal of Cancer, vol. 119, no. 11, pp. 2657-2664, 2006.

[23] D. S. Chan, R. Lau, D. Aune et al., "Red and processed meat and colorectal cancer incidence: meta-analysis of prospective studies," PLoS ONE, vol. 6, no. 6, article e20456, 2011.

[24] E. Cho, S. A. Smith-Warner, D. Spiegelman et al., "Dairy foods, calcium, and colorectal cancer: a pooled analysis of 10 cohort studies," Journal of the National Cancer Institute, vol. 96, pp. 1015-1022, 2004.

[25] Y. Park, D. J. Hunter, D. Spiegelman et al., "Dietary fiber intake and risk of colorectal cancer: a pooled analysis of prospective cohort studies," The Journal of the American Medical Association, vol. 294, pp. 2849-2857, 2005.

[26] E. Cho, S. A. Smith-Warner, J. Ritz et al., "Alcohol intake and colorectal cancer: a pooled analysis of 8 cohort studies," Annals of Internal Medicine, vol. 140, pp. 603-613, 2004.

[27] A. L. Klatsky, M. A. Armstrong, G. D. Friedman, and R. A. Hiatt, "The relations of alcoholic beverage use to colon and rectal cancer," American Journal of Epidemiology, vol. 128, no. 5, pp. 1007-1015, 1988.

[28] G. N. Stemmermann, A. Nomura, and P. H. Chyou, "The influence of dairy and nondairy calcium on subsite large-bowel cancer risk," Diseases of the Colon and Rectum, vol. 33, no. 3, pp. 190-194, 1990.

[29] A. A. Razzak, A. S. Oxentenko, R. A. Vierkant et al., "Alcohol intake and colorectal cancer risk by molecularly defined subtypes in a prospective study of older women," Cancer Prevention Research, vol. 4, pp. 2035-2043, 2011.

[30] E. Giovannucci, E. B. Rimm, M. J. Stampfer, G. A. Colditz, A. Ascherio, and W. C. Willett, "Intake of fat, meat, and fiber in relation to risk of colon cancer in men," Cancer Research, vol. 54, no. 9, pp. 2390-2397, 1994.

[31] A. Chao, M. J. Thun, C. J. Connell et al., "Meat consumption and risk of colorectal cancer," The Journal of the American Medical Association, vol. 293, pp. 172-182, 2005.

[32] S. C. Larsson, J. Rafter, L. Holmberg, L. Bergkvist, and A. Wolk, "Red meat consumption and risk of cancers of the proximal colon, distal colon and rectum: the Swedish Mammography Cohort," International Journal of Cancer, vol. 113, no. 5, pp. 829834, 2005.

[33] T. Norat, S. Bingham, P. Ferrari et al., "Meat, fish, and colorectal cancer risk: the European Prospective Investigation into cancer and nutrition," Journal of the National Cancer Institute, vol. 97, no. 12, pp. 906-916, 2005.

[34] Y. Sato, N. Nakaya, S. Kuriyama, Y. Nishino, Y. Tsubono, and I. Tsuji, "Meat consumption and risk of colorectal cancer in Japan: the Miyagi cohort study," European Journal of Cancer Prevention, vol. 15, no. 3, pp. 211-218, 2006.

[35] A. J. Cross, L. M. Ferrucci, A. Risch et al., "A large prospective study of meat consumption and colorectal cancer risk: an investigation of potential mechanisms underlying this association," Cancer Research, vol. 70, no. 6, pp. 2406-2414, 2010. 
[36] A. Shin, J. Joo, J. Bak et al., "Site-specific risk factors for colorectal cancer in a Korean population," PLoS One, vol. 6, article e23196, 2011.

[37] K. A. Steinmetz, L. H. Kushi, R. M. Bostick, A. R. Folsom, and J. D. Potter, "Vegetables, fruit, and colon cancer in the Iowa women's health study," American Journal of Epidemiology, vol. 139, no. 1, pp. 1-15, 1994.

[38] C. S. Fuchs, E. L. Giovannucci, G. A. Colditz et al., "Dietary fiber and the risk of colorectal cancer and adenoma in women," New England Journal of Medicine, vol. 340, no. 3, pp. 169-176, 1999.

[39] S. C. Larsson, E. Giovannucci, L. Bergkvist, and A. Wolk, "Whole grain consumption and risk of colorectal cancer: a population-based cohort of 60000 women," British Journal of Cancer, vol. 92, no. 9, pp. 1803-1807, 2005.

[40] A. M. Nomura, J. H. Hankin, B. E. Henderson et al., "Dietary fiber and colorectal cancer risk: the multiethnic cohort study," Cancer Causes and Control, vol. 18, no. 7, pp. 753-764, 2007.

[41] A. Schatzkin, T. Mouw, Y. Park et al., "Dietary fiber and wholegrain consumption in relation to colorectal cancer in the NIHAARP Diet and Health Study," American Journal of Clinical Nutrition, vol. 85, no. 5, pp. 1353-1360, 2007.

[42] G. C. Kabat, J. M. Shikany, S. A. Beresford et al., "Dietary carbohydrate, glycemic index, and glycemic load in relation to colorectal cancer risk in the Women's Health Initiative," Cancer Causes and Control, vol. 19, no. 10, pp. 1291-1298, 2008.

[43] R. Egeberg, A. Olsen, S. Loft et al., "Intake of wholegrain products and risk of colorectal cancers in the Diet, Cancer and Health cohort study," British Journal of Cancer, vol. 103, no. 5, pp. 730-734, 2010.

[44] N. Murphy, T. Norat, P. Ferrari et al., "Dietary fibre intake and risks of cancers of the colon and rectum in the European Prospective Investigation into Cancer and Nutrition (EPIC)," PLoS One, vol. 7, article e39361, 2012.

[45] M. L. McCullough, A. S. Robertson, C. Rodriguez et al., "Calcium, vitamin D, dairy products, and risk of colorectal cancer in the Cancer Prevention Study II Nutrition Cohort (United States)," Cancer Causes and Control, vol. 14, no. 1, pp. 1-12, 2003.

[46] S. C. Larsson, L. Bergkvist, and A. Wolk, "High-fat dairy food and conjugated linoleic acid intakes in relation to colorectal cancer incidence in the Swedish Mammography Cohort," American Journal of Clinical Nutrition, vol. 82, no. 4, pp. 894-900, 2005.

[47] S. C. Larsson, L. Bergkvist, J. Rutegård, E. Giovannucci, and A. Wolk, "Calcium and dairy food intakes are inversely associated with colorectal cancer risk in the Cohort of Swedish Men," American Journal of Clinical Nutrition, vol. 83, no. 3, pp. 667$673,2006$.

[48] P. Terry, J. A. Baron, L. Bergkvist, L. Holmberg, and A. Wolk, "Dietary calcium and vitamin D intake and risk of colorectal cancer: a prospective cohort study in women," Nutrition and Cancer, vol. 43, no. 1, pp. 39-46, 2002.

[49] K. Wu, W. C. Willett, C. S. Fuchs, G. A. Colditz, and E. L. Giovannucci, "Calcium intake and risk of colon cancer in women and men," Journal of the National Cancer Institute, vol. 94, no. 6, pp. 437-446, 2002.

[50] A. Flood, U. Peters, N. Chatterjee, J. V. Lacey Jr., C. Schairer, and A. Schatzkin, "Calcium from diet and supplements is associated with reduced risk of colorectal cancer in a prospective cohort of women," Cancer Epidemiology Biomarkers and Prevention, vol. 14, no. 1, pp. 126-132, 2005.
[51] J. Ishihara, M. Inoue, M. Iwasaki, S. Sasazuki, and S. Tsugane, "Dietary calcium, vitamin D, and the risk of colorectal cancer," American Journal of Clinical Nutrition, vol. 88, no. 6, pp. 15761583, 2008.

[52] A. H. Wu, A. Paganini-Hill, R. K. Ross, and B. E. Henderson, "Alcohol, physical activity and other risk factors for colorectal cancer: a prospective study," British Journal of Cancer, vol. 55, no. 6, pp. 687-694, 1987.

[53] E. Giovannucci, E. B. Rimm, A. Ascherio, M. J. Stampfer, G. A. Colditz, and W. C. Willett, "Alcohol, low-methionine-lowfolate diets, and risk of colon cancer in men," Journal of the National Cancer Institute, vol. 87, no. 4, pp. 265-273, 1995.

[54] A. Pedersen, C. Johansen, and M. Grønbæk, "Relations between amount and type of alcohol and colon and rectal cancer in a Danish population based cohort study," Gut, vol. 52, no. 6, pp. 861-867, 2003.

[55] M. Akhter, S. Kuriyama, N. Nakaya et al., "Alcohol consumption is associated with an increased risk of distal colon and rectal cancer in Japanese men: the Miyagi Cohort Study," European Journal of Cancer, vol. 43, no. 2, pp. 383-390, 2007.

[56] P. Ferrari, M. Jenab, T. Norat et al., "Lifetime and baseline alcohol intake and risk of colon and rectal cancers in the European prospective investigation into cancer and nutrition (EPIC)," International Journal of Cancer, vol. 121, no. 9, pp. 2065-2072, 2007.

[57] B. W. C. Bongaerts, P. A. van den Brandt, R. A. Goldbohm, A. F. P. M. de Goeij, and M. P. Weijenberg, "Alcohol consumption, type of alcoholic beverage and risk of colorectal cancer at specific subsites," International Journal of Cancer, vol. 123, no. 10, pp. 2411-2417, 2008.

[58] J. Y. Park, C. C. Dahm, R. H. Keogh et al., "Alcohol intake and risk of colorectal cancer: results from the UK Dietary Cohort Consortium," British Journal of Cancer, vol. 103, no. 5, pp. 747756, 2010.

[59] M. Egger, G. D. Smith, and J. A. Sterne, "Uses and abuses of meta-analysis," Clinical Medicine, vol. 1, pp. 478-484, 2001.

[60] J. Lin, S. M. Zhang, N. R. Cook, J. E. Manson, I. M. Lee, and J. E. Buring, "Intakes of calcium and vitamin D and risk of colorectal cancer in women," American Journal of Epidemiology, vol. 161, no. 8, pp. 755-764, 2005.

[61] S. A. Bingham, R. Hughes, and A. J. Cross, "Effect of white versus red meat on endogenous $\mathrm{N}$-nitrosation in the human colon and further evidence of a dose response," Journal of Nutrition, vol. 132, no. 11, pp. 3522S-3525S, 2002.

[62] A. C. Povey, C. N. Hall, A. F. Badawi, D. P. Cooper, and P. J. O'Connor, "Elevated levels of the pro-carcinogenic adduct, $\mathrm{O}(6)$-methylguanine, in normal DNA from the cancer prone regions of the large bowel," Gut, vol. 47, no. 3, pp. 362-365, 2000.

[63] A. Hague, A. M. Manning, K. A. Hanlon, L. I. Huschtscha, D. Hart, and C. Paraskeva, "Sodium butyrate induces apoptosis in human colonic tumour cell lines in a p53-independent pathway: implications for the possible role of dietary fibre in the prevention of large-bowel cancer," International Journal of Cancer, vol. 55, no. 3, pp. 498-505, 1993.

[64] W. Scheppach and F. Weiler, "The butyrate story: old wine in new bottles?" Current Opinion in Clinical Nutrition and Metabolic Care, vol. 7, no. 5, pp. 563-567, 2004.

[65] J. M. Wong, R. de Souza, C. W. C. Kendall, A. Emam, and D. J. Jenkins, "Colonic health: fermentation and short chain fatty acids," Journal of Clinical Gastroenterology, vol. 40, no. 3, pp. 235-243, 2006. 
[66] W. E. Roediger, "Role of anaerobic bacteria in the metabolic welfare of the colonic mucosa in man," Gut, vol. 21, no. 9, pp. 793-798, 1980.

[67] S. A. Lamprecht and M. Lipkin, "Chemoprevention of colon cancer by calcium, vitamin D and folate: molecular mechanisms," Nature Reviews Cancer, vol. 3, no. 8, pp. 601-614, 2003.

[68] G. Pöschl and H. K. Seitz, "Alcohol and cancer," Alcohol and Alcoholism, vol. 39, no. 3, pp. 155-165, 2004.

[69] U. A. Simanowski, F. Stickel, H. Maier, U. Gärtner, and H. K. Seitz, "Effect of alcohol on gastrointestinal cell regeneration as a possible mechanism in alcohol-associated carcinogenesis," Alcohol, vol. 12, no. 2, pp. 111-115, 1995. 


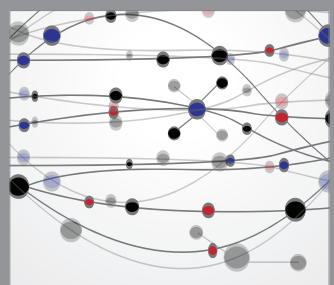

The Scientific World Journal
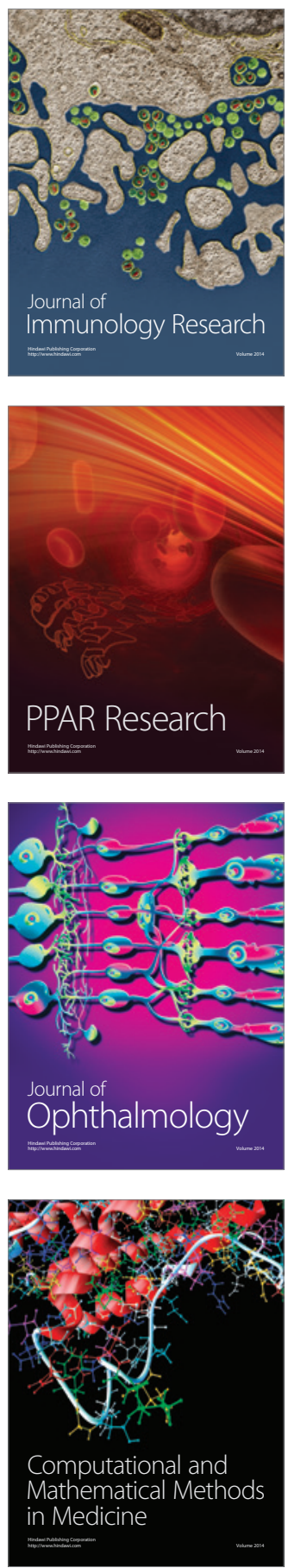

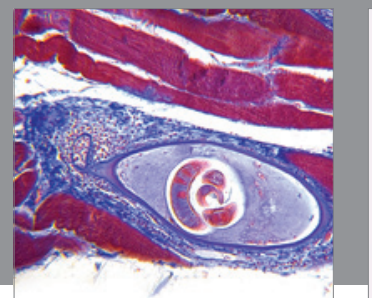

Gastroenterology

Research and Practice
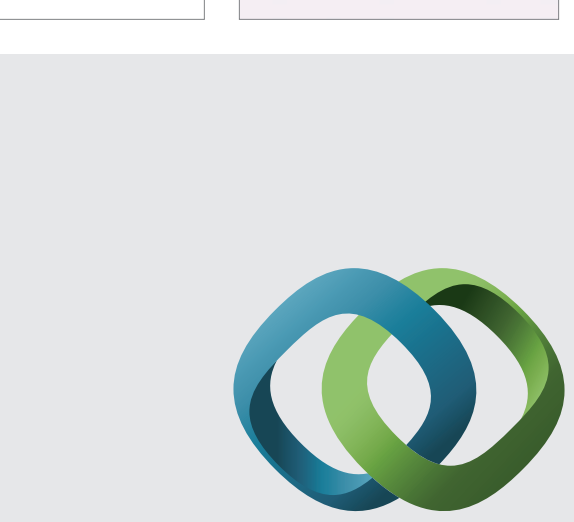

\section{Hindawi}

Submit your manuscripts at

http://www.hindawi.com
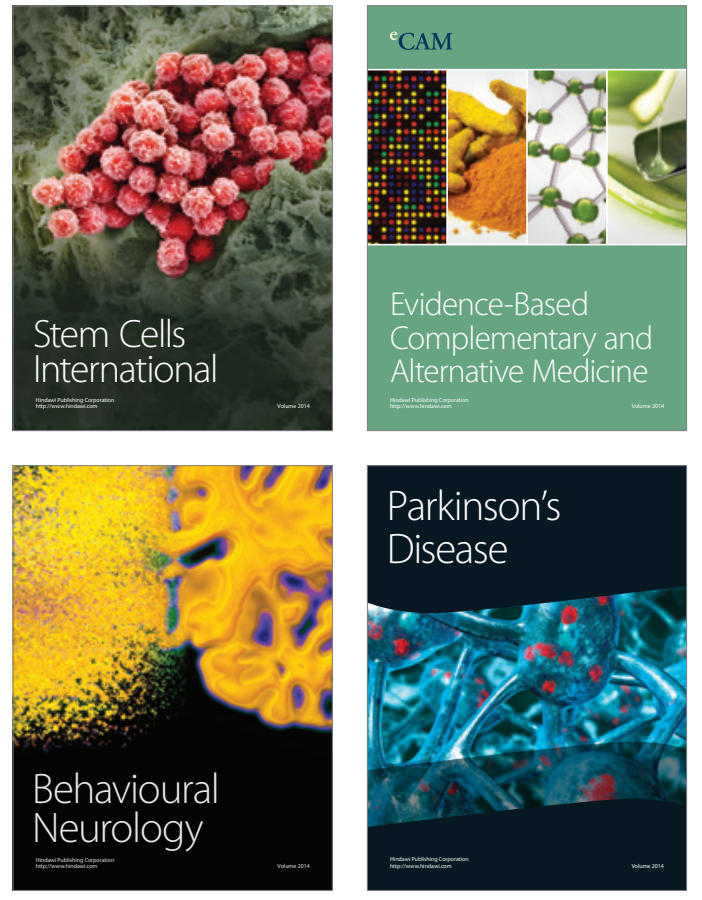
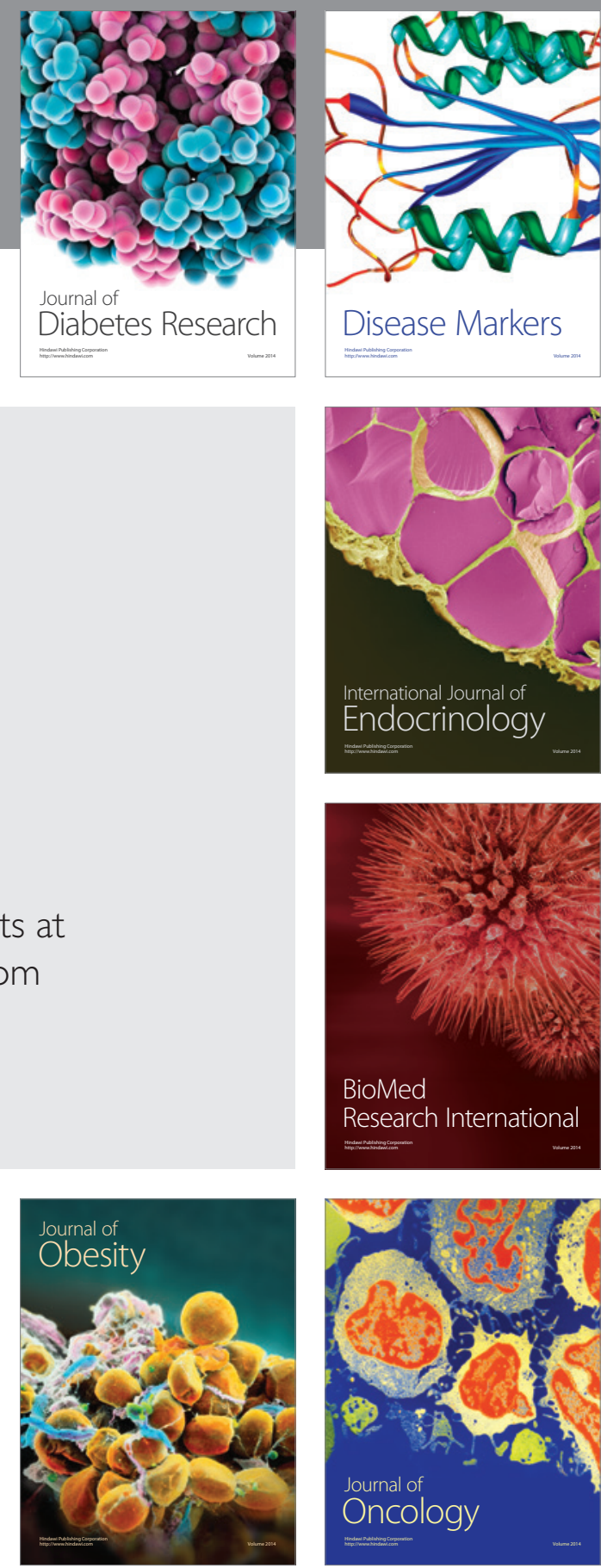

Disease Markers
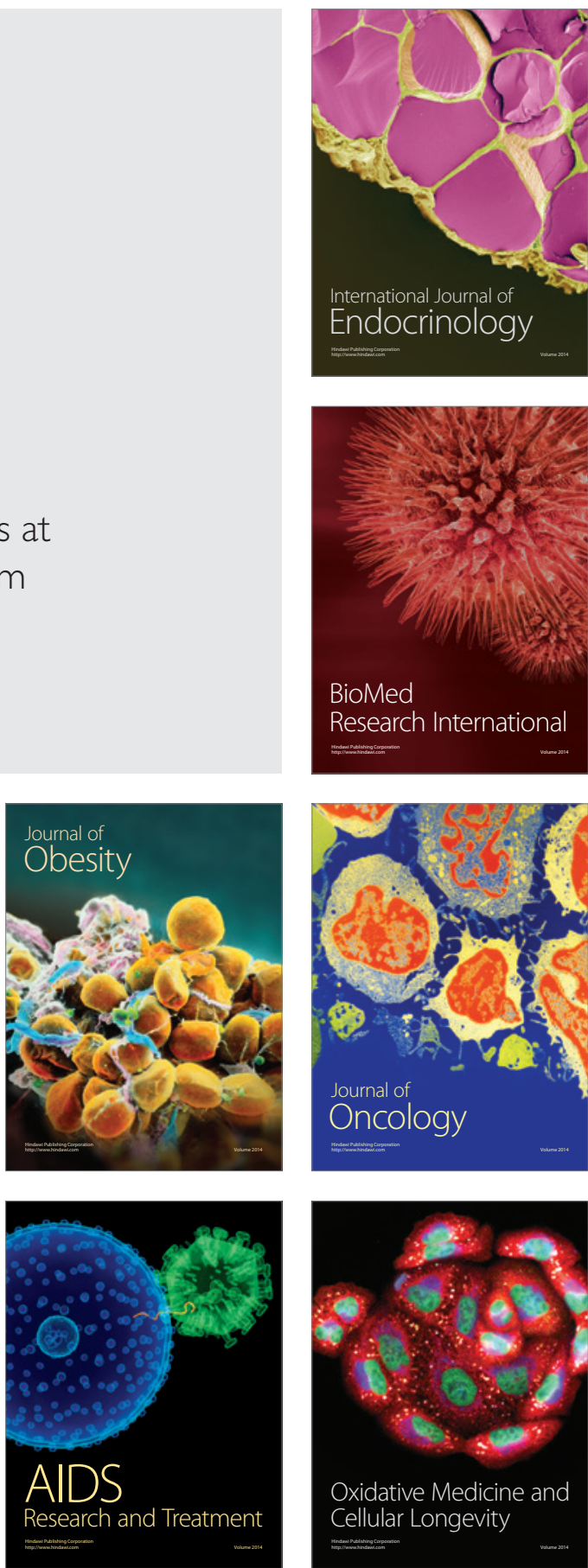